\title{
CORRECTION
}

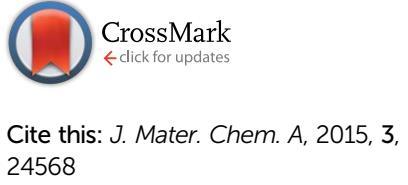

www.rsc.org/MaterialsA

\section{Correction: Polymerized ionic liquid block copolymers for electrochemical energy}

Kelly M. Meek and Yossef A. Elabd*

Correction for 'Polymerized ionic liquid block copolymers for electrochemical energy' by Kelly M. Meek et al., J. Mater. Chem. A, 2015, DOI: 10.1039/c5ta07170d.

Ref. 32 of the above Highlight has now been accepted and has the citation information below.

32 J. R. Nykaza, Y. Ye, R. L. Nelson, A. C. Jackson, F. L. Beyer, E. M. Davis, K. Page, S. Sharick, K. I. Winey and Y. A. Elabd, Soft Matter, 2015, DOI: 10.1039/C5sm02053k.

The Royal Society of Chemistry apologises for these errors and any consequent inconvenience to authors and readers. 